\title{
YIELDCO AS A PERSPECTIVE INVESTMENT VEHICLE
}

\author{
Zhanna V. PISARENKO ${ }^{1 *}$, Natalia P. KUZNETSOVA², \\ Nguyen Cahn TOAN ${ }^{3}$, Leonid A. IVANOV (1) 4 \\ ${ }^{1,2}$ Risk Management and Insurance Department, Saint Petersburg state University, \\ 7-9 Universitetskaya nab., 199034 Saint Petersburg, Russian Federation \\ ${ }^{3}$ Vietnam Academy of Social Sciences (VAON), 1 Liễu Giai, Ba Đinh, Hanoi, Socialist Republic of Vietnam \\ ${ }^{4}$ Russian Academy of Engineering, Gazetnnyy Pereulok, 9, 125009 Moscow, Russian Federation
}

Received 28 February 2021; accepted 01 April 2021

\begin{abstract}
Purpose - the purpose of the article is to assess the investment potential of YieldCos as an innovative pension vehicle and determine the risks that may arise in connection with them. Methods used: empirical analyses, comparisons, statistical analyses.

Research methodology - empirical research, comparative analysis, statistical analyses.

Findings - in the paper we compared the new investment vehicle YieldCos (green) and a traditional investment vehicle energy companies (non-green). It was found that the correlation of YieldCos with the market indices is similar to nongreen companies. But YieldCos are more exposed to risks than energy companies. That may offset their attractiveness as long term investment vehicle. It is necessary to continue research for this investment vehicle during the period of global financial volatility and crash of crude oil price.

Research limitations - the authors study the raise of the new investment vehicle - YieldCos, during the period from 2013 to 2018 (pre Covid-19 Era).

Practical implications - YieldCos focus on investors interests, raising money in an environmental projects (namely renewable energy), and provide combination of high yield and high income growth. Aforesaid characteristics are attractive for institutional investors that are currently experiencing a lack of resources to meet their obligations.

Originality/Value - new investment vehicle is becoming a part of the overall socially responsible investment universe. We have taken the first step in the comparative evaluation of traditional and innovative types of investment instruments. Showed the prospects of a new environmentally oriented tool. It is necessary to continue research of this investment vehicle during the period of global financial volatility, changing landscape of energy resources and stakeholders rising influence.
\end{abstract}

Keywords: YieldCos, pension fund, investment vehicle, renewable energy.

JEL Classification: G11, G23.

Conference topic: Contemporary Financial Management.

\section{Introduction}

Institutional investors are a strategically important part of the global financial market. In 2019 the assets of OECD pension funds amounted to more than \$ 27.6 trillion (Organisation for Economic Co-operation and Development $[\mathrm{OECD}], 2019)$. Along with the active process of investing in the economy, the obligations of pension funds - an important component of households' welfare. They account for more than $30 \%$ of the savings of the households. Such indicators are comparable only to deposits, i.e. they actively compete with traditional banks for the savings of the population.

At the same time, institutional investors are to decide which assets to include into their portfolio and when to do so. Conservatism of institutional investors in allocating investments to the "new" asset classes leads to the risk improper diversification, and also provokes the possibility of missing out the high potential profitability. However,

*E-mail: z.pisarenko@spbu.ru

(C) 2021 Authors. Published by Vilnius Gediminas Technical University. This is an open-access article distributed under the terms of the Creative Commons Attribution (http://creativecommons.org/licenses/by/4.0/) License, which permits unrestricted use, distribution, and reproduction in any medium, provided the original author and source are credited. 
new alternative asset classes, that were not previously included in investment portfolios, also expose institutional investors at risk.

Thus, it is obvious that an institutional investor could achieve portfolio diversification via the choice of an asset classes. Portfolio diversification of pension funds is rather a crucial topic at the times of long-term low interest rates and increasing risks in the world economy, current pension reforms that provide multi variant choice for future retirees and world pandemic. For the best diversification, it is necessary to include into the portfolio those assets that are least correlated with the vulnerable stock market and the investment portfolio, in particular. Alternative investments could help institutional investors in achieving this goal.

More than that, defined benefit pension funds are forced to take on additional external risks. Pension liabilities to the Fund's clients (beneficiaries) have a longer term than pension assets, so a prolonged reduction in interest rates increases the present value of pension funds' liabilities, thereby reducing their payment capacity ${ }^{1}$. As noted by Di Maggio and Kacperczyk (2017), a similar situation is observed with money market funds. To correct the situation, pension funds increase the investment period, focusing on longer-term projects and increasing the share in the portfolio of alternative investment classes. According to the International Monetary Fund, Pension funds have increased the share of alternative assets in their portfolios quite significantly between 2007 and 2018 .

The functional characteristic of alternative investments is the possibility to reduce the correlation between the stock market and the investment portfolio of the institutional investor. Typically, alternative investments include: real estate, private equity, and commodities (Chambers, 2018). More complicated alternative investments are hedge funds' investments, managed futures, distressed securities, as well as popular investments related to the green economy: green bonds, asset-backed securities (ABS) and Yield Companies (YieldCos) ${ }^{2}$.

Yield Companies can become a reasonable choice for institutional investors at the times of declining revenues for other financial instruments. But on the other hand the YieldCos are exposed to extra risks.

Green investments are part of the overall socially responsible investment, but they occupy a closer niche. Some authors (Inderst et al., 2012) define green investment as any activity in the field of sustainable energy, energy efficiency or water management. Bloomberg (2019) believes that, green instruments should be considered more broadly and uses the concept of green Finance. Global Sustainable Investment Alliance [GSIA] (2016) defines green investments as "green" projects that can insure social benefits, and the use of funds from the placement of green bonds should be determined by the Issuer based on its main goals for the relevant projects. Bonds that intentionally combine environmental and social projects are called sustainability bonds (International Capital Market Association [ICMA], 2018).

Today, almost all institutional investors include into their investment portfolio green assets. Although there is no single standard applied to green investments, nor is there a mechanism for monitoring compliance with the standards. Nevertheless, so-called green investing attracts a lot of interest from private equity.

If we consider the concept of green investing from the point of investment vehicles, we can distinguish fixed income (primarily green bonds), direct investment (green equity investments), and green projects (Porfir'ev, 2016). But the essence of "going green" is investing in stocks, bonds or infrastructure projects related to the environment, that is, the development and introduction of alternative energy sources, processing, waste utilization, and reduction of carbon dioxide emissions.

Long-term forecasts of climate change scenarios show the potential risk to the investment portfolio of pension funds. For holistic risk management, it is necessary to respond to identified risks, quantify them, and look forward to hedge them at minimal costs. Investments in green technologies, business or infrastructure related to the environment are less sensitive to climate change, so they are of the ways to reduce such risks. The investment horizon of pension funds is rather long, so the climate agenda and environmental concerns are of great importance for them. Potentially pension funds and other institutional investors can finance green initiatives. The purpose of the study: to assess the investment potential of Yield Companies (YieldCos) as an innovative investment vehicle and determine the risks that may arise in connection with them (pre Covid-19 Era).

Green equity indices such as FTSE4Good, DJSI, S\&P Global Eco Index, S\&P Global Water Index, (Sustainalytics, 2019) and others can influence investors' decisions. According to the OECD survey, 22 of the 77 largest pension funds invest in a portfolio of green projects. According to (Sustainalytics, 2019), about $\$ 58.8$ billion of responsible and social investments were issued in 2018. The green investment topic does not remain without attention. The underdevelopment of the institutional environment for creating a system of environmental investment notice (Richter at al., 2015). Some researches (Bokarev et al., 2017) analyze the current state of green investment in the Russian Federation and identify the vagueness of state policy in regulating the transition of national business to a "green" economy. Many research works focus on specific aspects of it. For example, Gatzert and Kosub (2014) analyzed the investment opportunities of insurance companies in infrastructure projects under more stringent capital requirements.

\footnotetext{
1 "Pension freedoms" proclaimed in 2015 in the UK, which allow a pensioner to buy out as an investor and independently invest their retirement savings (https://www.financial-ombudsman.org.uk/consumers/complaints-can-help/pension).

${ }^{2}$ YieldCos offer combination of potential high yield and high income growth through the exposure to renewable energy, which have been some of the fastest growth areas in the last few years.
} 
Extra emerging risks arising from YieldCo studied (Arnold \& Azar, 2015). Gordon (Gordon \& Monk, 2019; Gordon, 2017) presented a summary of the activities of financial intermediaries (as opposed to traditional banks) that have launched a pool of investment projects into urban European infrastructure and analyzed long term investors engagement in innovative investment activities. Pisarenko et al. (2017) compared social investment projects under the pressure of pension reforms. In et al. (2018) investigated options for long-term financing into environmental projects and concluded that investment opportunities (and risks) cannot be effectively distributed among institutional investors due to the fragmented nature of investor networks and a large information asymmetry between different categories of investors and companies. Some researchers (La Monaca et al., 2018) argued that found that non-American YieldCos can also generate profits, even without using American management style.

International organizations such as the OECD, the World Bank (Levy, 2017), the International Labor organization; major international consulting companies monitor changes ( $\mathrm{PwC}, 2017)$, publish annual reviews of pension and insurance markets and pension system reforms, monitor the development of infrastructure investment. The concept of the special companies aimed at investor's interest (more than $90 \%$ of the profit was to distribute among the investors) appeared for the first time in the United States. Such companies attracted attention of investors for tax optimization purposes. The phenomenon emerged in the second half of the XX century, new companies (actually, REITs real estate investment trust) were extremely popular because they created a new investment vehicle for investors who did not want or could not directly own property. The popularity led to the creation of Master Limited Partnerships (MLPs) in the 1980 s, a similar investment vehicle, but with a focus on natural resources. YieldCo's primary goal (similar to MLPs and REITs) is to own and manage assets, and distribute revenue among shareholders through projected longterm cash flows, that is to pay steady dividends to shareholders. The main difference is that YieldCos are mainly focused on renewable energy projects, while MLPs focus on oil and gas production and processing assets, and REITs focus on the real estate. Now there are many YieldCos in renewable energy business.

The $2012^{\text {th }}$ was the year when the first YieldCo was founded. As the economic situation was rather favorable, in only 3 years, the capitalization of 10 YieldCos have reached almost $\$ 18$ billion. They showed significant growth, due to the fact that many considered YieldCos as a good way to capitalize on the increasing trend for renewable energy. This is especially true in the United States, where large companies separate assets that generate renewable energy and set up public subsidiaries as special vehicles to raise additional capital.

Yieldco is a public company, which is created by the parent company. The parent company combines renewable and/or conventional long-term contractual operating assets in order to generate predictable cash flows. Usually Yieldco focuses on dividend growth therefore it distributes dividends to investors annually or quarterly. Such investments can be attractive to shareholders because they expect low-risk returns that are projected to increase over time. The capital raised can be used to pay off expensive debts or finance new projects at rates lower than those available through taxbased financing (Quesnel et al., 2016).

This is achieved by comparing incoming cash flows (income from assets) with expenses that exceed taxable income (expenses from depreciation and expenses on renewable assets). These "net operating costs" reduce the company's taxable income. Net operating costs can be "carried over" to taxable income from future periods, and therefore many YieldCos do not expect to pay significant income tax for several years. In addition, dividends may also receive favorable tax treatment at the shareholders level if the income is treated as a return on the original investment, rather than a return on the investment. When income is taxed only at one level, the company can raise capital from shareholders more profitably.

The parent company owns a majority interest in Yieldco (class B ordinary shares), while the public shares have a minority interest (class A ordinary shares). Profit from subsidiary is transferred to shareholders via this structure.

Renewable energy projects face some uncertainty at the development stage (Bradford, 2008), but once production is established, they tend to generate low-risk cash flows (Wesoff, 2016). YieldCos could be attractive to investors who accept risk or do not have any channels to invest capital in renewable energy sources. In exchange for the opportunity to invest in assets with a relatively low risk level, YieldCos investors usually receive 3-5\% return with the prospect of dividend growth up to $8-15 \%$. For example, the TerraForm Power Issuer is targeting a $15 \%$ annual growth for Cash Available for Distribution (CAD) over a three-year period. The investor's income is directly related on the operating efficiency of the underlying assets and the final CSD, $70-90 \%$ of which is distributed as dividends. YieldCos set up a dividend policy and methods for calculating funds available for distribution (CAD). CAD is the excess amount left after the expenses have been deducted from the income from operations.

For starting a Yieldco project, Parent Company should consider the risks of a potential negative impact on its credit rating. The fact is that the Parent Company transfers operating assets from its own balance sheet to the YieldCo's balance sheet. And if credit rating agencies perceive this change in assets to liabilities as a risk, they may cut the Parent Company's credit rating. In this research we conduct the empirical study of the YieldCo's investment characteristics which are of great interest for Pension Funds. Our focus is on the North American energy market, which is the leader in this field. 


\section{Research data and method used}

Our research focuses on YieldCos related to the green economy and Green Finance. They could be included in the universe of socially oriented investments (SRI). The basic concept of SRI is not generating super profits, but an evolutionary change in corporate governance towards greater responsibility to society. At the same time, there are risks associated with low profitability of SRI instruments based on the ESG principles. The novelty of the SRI concept is the prevalence of the public result on the private one (GSIA, 2016). That is, along with the financial result, there must be a socially significant result that contributes to the socio-economic development of the region (country) or world.

Research methods used in the paper: empirical research, comparative analysis, statistical analyses. Empirical research is an evidence-based approach to the interpretation of gathered data. The method is used primarily in quantitative research involving original collection of data, but also in secondary analyses and increasingly in qualitative research (Dan, 2017). The second method we used is a comparative analysis. It provides possibilities to find ways for system response to perturbations of its parameters (Bukhari, 2011). Within the framework of statistical analysis (namely correlation analysis) authors conducted, along with the sample statistical observation and grouping of statistical observation materials, evaluation the strength of relationship between two quantitative variables and an analysis of absolute and relative statistical values. The conducted research is based on the combination of the above mentioned methods.

The research is based the following methods of scientific research: empirical analyses, comparisons, statistical analyses. The authors suggested a hypothesis that the (YieldCos) could be innovative investment vehicle in short-term periods and bear extra the risks that may arise in connection with external shocks.

The research data was obtained from open sources on the Internet, official websites of Yield Companies and energy companies, international organizations (The World Bank, OECD, GSIA, etc.), international consulting and rating agencies (Yahoo! Finance, 2021; PWC etc.).

For our research we have selected the most famous recent projects of YieldCos and traditional companies from the energy sector of the North America. The sample includes companies 9 companies:

\section{YieldCos}

- Pattern Energy Group Inc. (PEGI) $)^{3}$ The USA

- NextEra Energy Partners, LP (NEP) ${ }^{5}$

- TerraForm Power, Inc. (TERP) ${ }^{6}$ The USA

- TransAlta Renewables Inc. (RNW.TO) ${ }^{8}$ Canada

\section{Energy companies (electric and gas utilities)}

- Duke Energy Corporation (DUK) ${ }^{4}$ The USA

- NextEra Energy, Inc. (NEE) The USA

- Dominion Energy, Inc. (D) ${ }^{7}$

- The Southern Company (SO) The USA

- Emera Incorporated (EMA.TO)

\section{Results and discussion}

Taking into account a short period of YieldCos existence, let's consider the entire period of their operations that is available via the open access. Figure 1 shows the profitability of YieldCos from our sample for the period 2013-2018.

As it is seen on the Figure 1, the overall trend of the share price, despite the turbulence of 2015, has a positive direction. Some experts (Deloitte, 2016; Project Finance International, 2014) explain it by the decline in oil prices during the period caused systemic uncertainty, undermining investors' confidence in peripheral markets. However, the main attractiveness for investors in this financial vehicle is in the regular cash flow in the form of dividends. Figures 2 and 3 present the profitability of YieldCo's and energy companies in focus, taking into account the quarterly dividend payment. As we can see, energy giants in 2015 did not react as significantly to price changes as YieldCos.

The expected quarterly return of each YieldCo is equal to: 8\% - Pattern Energy Group Inc. (PEGI), 8.3\% - NextEra Energy Partners, LP (NEP), 6.33\% - TerraForm Power, Inc. (TERP), 9.58\% - TransAlta Renewables Inc. (RNW. TO). Annually that comprises $16 \%, 16.6 \%, 12.7 \%$ and $19.2 \%$, respectively.

The second step is to consider the largest companies in the American and Canadian energy industries. The sample includes companies such as NextEra Energy, Inc. (NA) (USA), Duke Energy Corporation (DUCK) (USA), Dominion Energy, Inc. (D) (USA), The Southern Company (SO) (USA), Emera Incorporated (EMA.TO) (Canada). Table 1 shows investment characteristics and risks of Energy giants and YieldCos.

\footnotetext{
$\overline{3 \text { https://patternenergy.com/ }}$

4 http://www.duke-energy.com/

5 http://www.investor.nexteraenergypartners.com/

6 http://www.terraformpower.com/

${ }^{7}$ http://www.dominionenergy.com/

${ }^{8}$ http://www.transaltarenewables.com/
} 


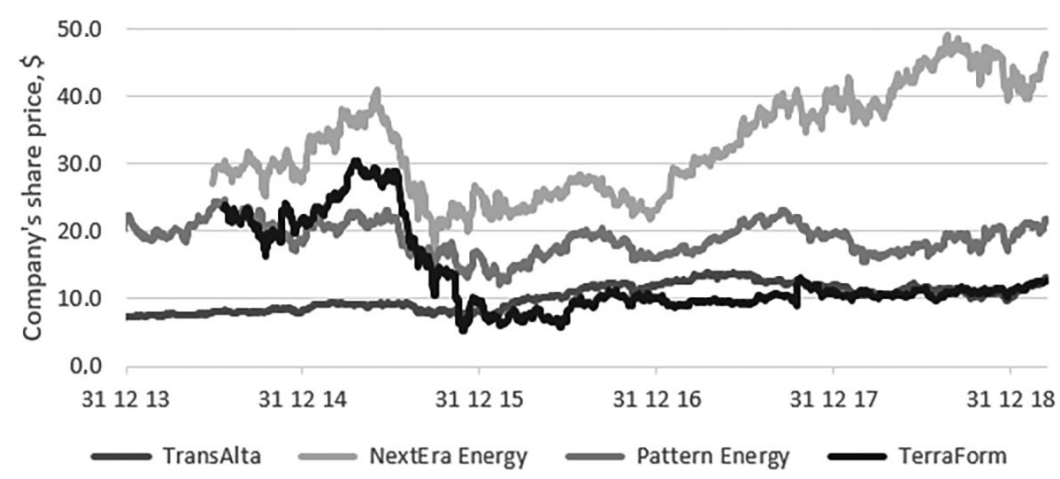

Figure 1. YieldCos dynamics of the share price, 2013-2018

(source: compiled by the authors on the basis of Finance.yahoo, 2019a;

Finance.yahoo, 2019b; Finance.yahoo, 2019c; Finance.yahoo, 2019d)

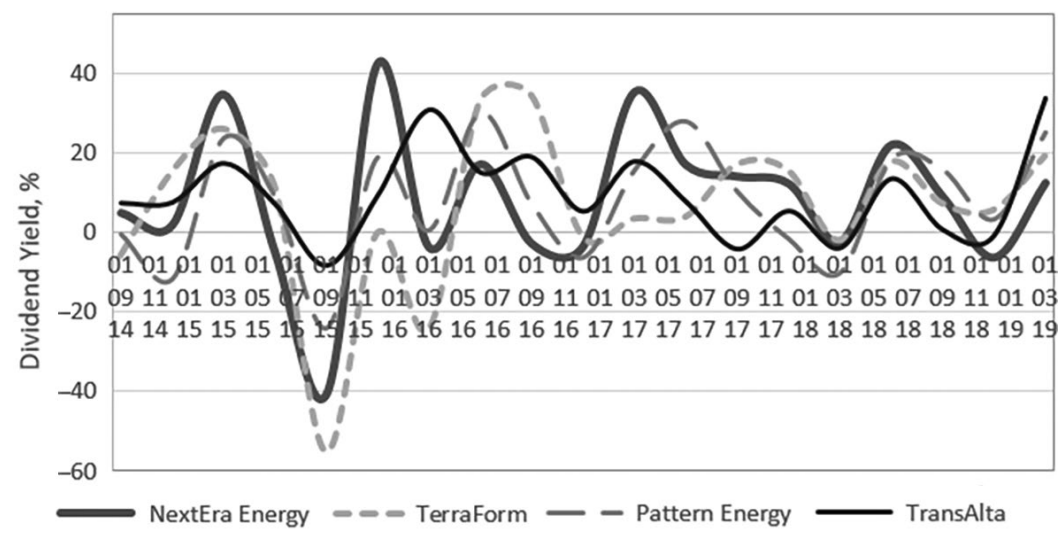

Figure 2. YieldCos quarterly yield, 2014-2019

(source: compiled by the authors on the basis of Finance.yahoo, 2019a;

Finance.yahoo, 2019b; Finance.yahoo, 2019c; Finance.yahoo, 2019d)

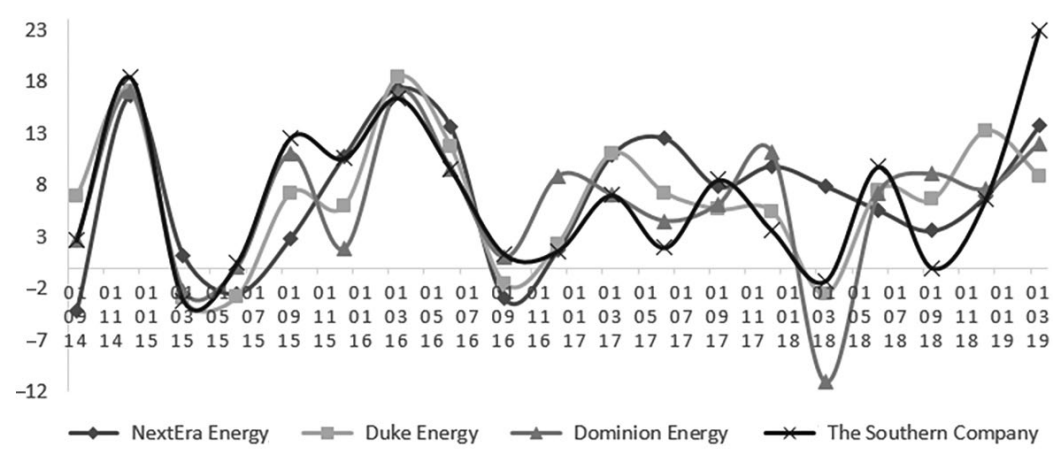

Figure 3. Energy companies, quarterly yield, 2014-2019

(source: compiled by the authors on the basis of Finance.yahoo, 2019e;

Finance.yahoo, 2019f; Finance.yahoo, 2019g; Finance.yahoo, 2019h)

Table 1. Investment characteristics and risks of YieldCos and energy companies, 2014-2019, \% (source: compiled by the authors)

\begin{tabular}{|l|c|c|c|c|c|c|c|c|c|c|}
\hline Indicator / Company name & $\begin{array}{c}\text { NextEra } \\
\text { Energy } \\
\text { Partners }\end{array}$ & $\begin{array}{c}\text { Pattern } \\
\text { Energy } \\
\text { Group }\end{array}$ & $\begin{array}{c}\text { TerraForm } \\
\text { Power }\end{array}$ & TransAlta & $\begin{array}{c}\text { Dominion } \\
\text { Energy }\end{array}$ & $\begin{array}{c}\text { Duke } \\
\text { Energy }\end{array}$ & Emera & $\begin{array}{c}\text { NextEra } \\
\text { Energy }\end{array}$ & $\begin{array}{c}\text { The } \\
\text { Southern } \\
\text { Company }\end{array}$ \\
\hline & \multicolumn{7}{|c|}{ Green } \\
\hline Average quarterly yield & 8.3 & 8.0 & 6.3 & 9.6 & 6.4 & 6.6 & 6.7 & 7.0 & 6.8 \\
\hline St. deviation quarterly & 18.7 & 14.9 & 20.5 & 11.1 & 6.7 & 6.2 & 5.8 & 6.5 & 7.1 \\
\hline Average annual yield & 16.6 & 16.0 & 12.7 & 19.2 & 12.7 & 13.2 & 13.4 & 14.0 & 13.7 \\
\hline Average annual st. deviation & 37.5 & 29.7 & 40.9 & 22.3 & 13.5 & 12.5 & 11.6 & 13.0 & 14.3 \\
\hline
\end{tabular}


As we can see from the results, the difference in profitability is insignificant, although YieldCos pay out to shareholders more than energy companies. The risk indicators - volatility of YieldCos profitability is two or three times higher than for energy companies. The largest standard deviation for "Green" sector is TerraForm Power (quarterly 20.5, annual - 40.9), for "Non Green" is only 7.1; annual - 14.3) (The Southern Company). In most cases, the amount of dividend payments of YieldCos is higher than that of traditional ones, which is to be expected. The volatility of YieldCo's stocks is offset by regular dividend payments, which are larger than those of energy companies.

Indeed, the YieldCos face certain risks. First of all, the wrong decisions of the company's management, which could be disastrous for companies. A striking example that confirms the risks of YieldCos is the bankruptcy of SunEdison in 2016 as a result of a failed investment project (\$ 16 billion for the development of solar energy). YieldCos are also subject to conflict of interest with Parent Company, tax policy changes, and new projects performance. Our hypothesis is confirmed.

Unfortunately for investors in TerraForm Power and TerraForm Global, the sponsor's financial distress resulted in management (which ran both SunEdison and its YieldCos) forcing the YieldCos not just to overpay for assets, but take on dangerous levels of debt as well. The business model of YieldCos brings up another major risk with YieldCos - the constant need for external capital growth. Because YieldCos' business models are very MLP-like, in that growth capital is derived from debt and equity markets, YieldCos are dependent on investor.

We have got other than expected results when conducting the correlation analysis of income from YieldCos and energy companies with S\&P 500 and FTSE4Good Global 100 indices (shown in Table 2). We assumed that there is a lower correlation of YieldCos with the market index than traditional ones. For this reason, they can be included into the investment portfolio of pension Funds for greater diversification.

However, according to the analysis, the relationship for both types of companies with the market indices is on average the same. It indicates equal opportunities for diversification both for YieldCos and energy companies.

Table 2. Correlation analysis income of YieldCos, energy companies with the S\&P 500, FTSE4Good Global 100 (source: compiled by the authors)

\begin{tabular}{|c|c|c|c|c|c|c|c|c|c|c|c|}
\hline Company & 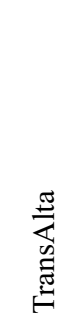 & 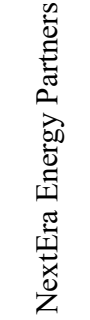 & 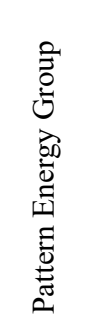 & 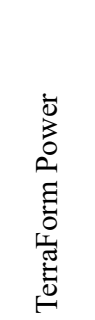 & 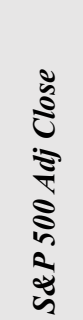 & 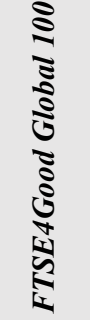 & 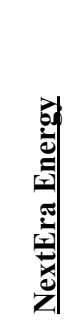 & 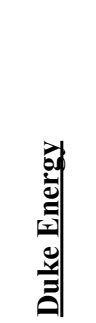 & 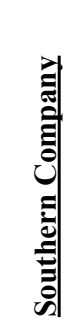 & 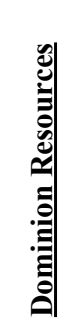 & 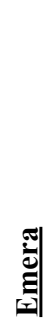 \\
\hline TransAlta & 1 & & & & & & & & & & \\
\hline NextEra Energy & 0.217 & 1 & & & & & & & & & \\
\hline Pattern Energy & 0.238 & 0.487 & 1 & & & & & & & & \\
\hline TerraForm Power & 0.177 & 0.323 & 0.398 & 1 & & & & & & & \\
\hline S\&P 500 Adj Close & $\underline{0.240}$ & $\underline{0.348}$ & $\underline{0.400}$ & $\underline{0.289}$ & 1 & & & & & & \\
\hline FTSE4Good Global 100 & $\underline{0.255}$ & $\underline{0.309}$ & $\underline{0.373}$ & $\underline{0.258}$ & $\underline{0.911}$ & 1 & & & & & \\
\hline NextEra Energy & 0.182 & 0.345 & 0.309 & 0.111 & $\underline{0.337}$ & $\underline{0.264}$ & 1 & & & & \\
\hline Duke Energy & 0.135 & 0.271 & 0.245 & 0.092 & $\underline{0.257}$ & $\underline{0.191}$ & 0.771 & 1 & & & \\
\hline Southern Company & 0.147 & 0.219 & 0.208 & 0.063 & $\underline{0.232}$ & $\underline{0.168}$ & 0.719 & 0.815 & 1 & & \\
\hline Dominion Resources & 0.164 & 0.274 & 0.306 & 0.132 & $\underline{0.311}$ & $\underline{0.239}$ & 0.735 & 0.760 & 0.714 & 1 & \\
\hline Emera & 0.256 & 0.164 & 0.198 & 0.095 & $\underline{0.216}$ & 0.204 & 0.322 & 0.345 & 0.300 & 0.321 & 1 \\
\hline
\end{tabular}

\section{Conclusions}

In the beginning of 2013, YieldCos had become a great vehicle for financing clean energy projects from a broad pool of investors. First YieldCos had changed the market of renewable energy. The conducted analysis of YieldCos showed that the expected yield of the new investment vehicle differs slightly from the traditional energy companies. The volatility of YieldCo's stocks is offset by regular dividend payments, which are larger than those of ordinary companies, which is an attractive investment quality for institutional investors. Combination of high yield and high income growth during 2013-2018 had been excellent for investors. 
The raise of the new investment vehicle provides valuable lessons for institutional investors. The future is at risk, the tightening market conditions must be compensated. Further research is required to analyze the positions of YieldCos during panic situations on financial markets (for example, those related to Coronavirus).

Today, renewable energy markets are still strongly linked to traditional energy carriers. Therefore, lower oil and traditional energy resources prices, and stakeholders' concerns about environmental risks and climate agenda could affect the quarterly payments of YieldCos in future perspective. However, in the long run, which is especially important for institutional investors, YieldCos could demonstrate more stable results. Pension funds and Insurance companies that include YieldCos in their portfolio could have solved two tasks: in the context of growing obligations of payments in the nearest future and the long-term decreasing interest rate, they could provide stable cash flow to ensure their obligations against participants of pension schemes and clients.

Our research is limited up to 2018, so we do not take into account the current disastrous situation in the financial markets in the context of the coronavirus pandemic. However, we can assume that projects aimed at creating socially approved green investments will help YieldCos overcome periods of recession and become a good income source for institutional investors.

We are now continuing our research. The pandemic of the new coronavirus infection has reshaped the financial markets, and has shown the need to include additional risk factors into the analysis. Moreover, it is necessary to see how YieldCos will "behave" in the new turbulent era. The focus of such companies on "green" investment tools can play a positive role in the future, since despite the pandemic, the basic attitudes of society to the use of environmentally friendly technologies, improving the natural environment, as well as the need to generate income in the long term period, remain.

\section{Acknowledgements}

The authors would like to thank the editor and the anonymous reviewers.

\section{Funding}

This work is supported by the Russian Foundation for Basic Research, RFBR [Grant number 19-510-92002].

\section{References}

Arnold, J., \& Azar, A. (2015). It's the end of the world as we knew it. YieldCo rout skews risk/reward. Deutsche Bank Market Research. https://dukespace.lib.duke.edu/dspace/bitstream/handle/10161/14205/Final\%20YieldCo\%20MP.pdf?sequence=1\&isAllowed $=\mathrm{y}$

Bloomberg. (2019). Green finance is now \$31 trillion and growing. https://www.bloomberg.com/graphics/2019-green-finance/

Bokarev, A. A., Yakovlev, I. A., \& Kabir, L. S. (2017). Green investments in Russia: search for priority directions. Financial Journal, 6, 40-49.

Bradford, T. (2008). Solar revolution. The economic transformation of the global energy industry. MIT Press.

Bukhari, S. A. H. (2011). What is comparative study. https://doi.org/10.2139/ssrn.1962328

Chambers, D. R., Black, K., \& Lacey, N. J. (2018). Alternative investments: a primer for investment professionals. CFA Institute Research Foundation Publications, 2018(1), 1-183. https://doi.org/10.2139/ssrn.3254577

Dan, V. (2017). Empirical and non-empirical methods. Wiley. https://www.researchgate.net/publication/309922961_Empirical_ and_Non-Empirical_Methods

Deloitte. (2016). Alternative thinking 2016: five game-changers powering the future of renewable energy. https://www2.deloitte. $\mathrm{com} /$ content/dam/Deloitte/global/Documents/Energy-and-Resources/gx-er-alternative-thinking.pdf

Di Maggio, M., \& Kacperczyk, M. (2017). The unintended consequences of the zero lower bound policy. Journal of Financial Economics, 123(1), 59-80. https://doi.org/10.1016/j.jineco.2016.09.006

Finance.yahoo. (2019a). Historical data. https://finance.yahoo.com/quote/RNW.TO/history?p=RNW.TO\&.tsrc=fin-srch

Finance.yahoo. (2019b). Historical data. https://finance.yahoo.com/quote/NEP/history?p=NEP\&.tsrc=fin-srch

Finance.yahoo. (2019c). Historical data. https://finance.yahoo.com/quote/PEGI/history?p=PEGI\&.tsrc=fin-srch

Finance.yahoo. (2019d). Historical data. https://finance.yahoo.com/quote/TERP/history?p=TERP\&.tsrc=fin-srch

Finance.yahoo. (2019e). Historical data. https://finance.yahoo.com/quote/NEE/history?p=NEE\&.tsrc=fin-srch

Finance.yahoo. (2019f). Historical data. https://finance.yahoo.com/quote/D/history?p=D\&.tsrc=fin-srch

Finance.yahoo. (2019g). Historical data. https://finance.yahoo.com/quote/DUK/history?p=DUK\&.tsrc=fin-srch

Finance.yahoo. (2019h). Historical data. https://finance.yahoo.com/quote/SO/history?p=SO\&.tsrc=fin-srch

Gatzert, N., \& Kosub, T. (2014). Insurers' investment in infrastructure: overview and treatment under Solvency II. The Geneva Papers on Risk and Insurance - Issues and Practice, 39, 351-372. https://doi.org/10.1057/gpp.2013.34

Global Sustainable Investment Alliance. (2016). Global Sustainable Investment Review 2016. http://www.gsi-alliance.org/wp-content/uploads/2017/03/GSIR_Review2016.F.pdf 
Gordon, L. C. (2017). Financial intermediation, infrastructure investment and regional growth. Area Development and Policy, 2(3), 217-236. https://doi.org/10.1080/23792949.2017.1345641

Gordon, L. C., \& Monk, A. (2019). Assessing long-term investor performance: principles, policies and metrics. SSRN Electronic Journal.

In, S. Y., Monk, A. H. B., \& Knox-Hayes, J. (2018). Financing energy innovation: new roles and functions of intermediation in clean energy (Working Paper). https://gpc.stanford.edu/publications/financing-energy-innovation-new-roles-and-functions-intermediation-clean-energy

Inderst, G., Kaminker, C., \& Stewart, F. (2012). Defining and measuring green investments: implications for institutional investors asset al.ocations (OECD Working Papers on Finance, Insurance and Private Pensions, No. 24). OECD Publishing.

International Capital Market Association. (2018). Green Bond Principles (GBP). https://www.icmagroup.org/sustainable-finance/ the-principles-guidelines-and-handbooks/green-bond-principles-gbp/\#: :text=The\%20Green\%20Bond\%20Principles\%20(GBP,issuance $\% 20 \mathrm{of} \% 20 \mathrm{a} \% 20$ green $\% 20$ bond

La Monaca, S., Assereto, M., \& Byrne, J. (2018). Clean energy investing in public capital markets: portfolio benefits of Yieldcos. Energy Policy, 121, 383-393. https://doi.org/10.1016/j.enpol.2018.06.028

Levy, J. (2017). Risk and capital requirements for infrastructure investment in emerging market and developing economies. https:// www.worldbank.org/

Organisation for Economic Co-operation and Development. (2019). Pension funds in figures. https://www.oecd.org/pensions/ private-pensions/Pension-Funds-in-Figures-2019.pdf

Pisarenko, Z. V., Kuznetsova, N. P., \& Chernova, G. V. (2017). Comparison of pension reforms in growing giants countries: case of China and Russia [Conference presentation]. International Conference "New Challenges of Economic and Business", University of Latvia, Riga. http://www.bvef.lu.lv/fileadmin/user_upload/lu_portal/projekti/evf_conf2017/Abstracts.pdf

Porfir'ev, B. N. (2016). Green trends in the global financial system. Mirovaya ekonomika i mezhdunarodnye otnosheniya, 60, 5-16.

Project Finance International. (2014). Yieldcos reprice renewable equity. PFI yearbook 2015. http://www.pfie.com/yieldcos-reprice-renewable-equity/21176767.fullarticle

PwC. (2017). Global infrastructure investment. The role of private capital in the delivery of essential assets and services. https:// www.pwc.com/

Quesnel, K., Ajami, N. K., \& Wyss, N. (2016). Tapping into alternative ways to fund innovation and multi-purpose water projects: a financing framework from the electricity sector. Stanford Woods Institute for the Environment. https://waterinthewest. stanford.edu/sites/default/files/Woods\%20Funding\%20Water\%20Projects\%20Whitepaper\%20v09.pdf

Richter, K. K., Pakhomova, N. V., Malyshkov, G. B., \& Bondarenko, Yu. P. (2015). Formation of demand for environmental innovations: is there enough institutional support? Problems of Modern Economy, 2(54), 15-27.

Sustainalytics. (2019). Company ESG risk ratings. https://www.sustainalytics.com/esg-ratings/

Wesoff, E. (2016). SunEdison: a timeline of the biggest corporate implosion in US solar history. Greentech Media. https://www. greentechmedia.com/articles/read/sunedison-the-biggest-corporate-implosion-in-us-solar-history 